\title{
Erratum to: Developing Outcome Measures for Criminal Justice Information Sharing: A Study of a Multi-Jurisdictional Officer Notification System for Policing Sex Offenders in Southern California
}

\author{
Stephanie A. Kovalchik ${ }^{1}$ - Erinn Herberman ${ }^{2}$. \\ Katie Mugg $^{2} \cdot$ Brian A. Jackson $^{3}$
}

Published online: 23 April 2016

(C) Southern Criminal Justice Association 2016

\section{Erratum to: Am J Crim Just (2016) \\ DOI 10.1007/s12103-016-9345-7}

The following acknowledgement was omitted from the originally published version of this article:

This publication was made possible by Award Number 2013-IJ-CX-K001 awarded by the National Institute of Justice, Office of Justice Programs. The opinions, findings, and conclusions or recommendations expressed in this publication are those of the authors and do not necessarily reflect the views of the Department of Justice.

The online version of the original article can be found at http://dx.doi.org/10.1007/s12103-016-9345-7.

\section{Stephanie A. Kovalchik}

s.a.kovalchik@gmail.com

$\triangle$ Brian A. Jackson

bjackson@ rand.org

1 RAND Corporation, 1776 Main Street, Santa Monica, CA, USA

2 ARJIS, San Diego, CA, USA

3 RAND Corporation, 1200 S Hayes St, Arlington, VA, USA 